\title{
Clinical study of headache with special reference to ophthalmic cause
}

\author{
Shashi Jain ${ }^{1}$, Shivcharan Lal Chandravanshi ${ }^{1}$, Laxmi Dukariya ${ }^{1}$, Eva Rani Tirkey ${ }^{1}$, Sheel Chandra Jain ${ }^{2}$ \\ ${ }^{1}$ Department of Ophthalmology, Shyam Shah Medical College, Rewa, 486 001, Madhya Pradesh, India. \\ ${ }^{2}$ Anupam Nursing Home, Rewa, 486 001, Madhya Pradesh, India. \\ Correspondence to: Shashi Jain, E-mail: mailto:shashimala5@yahoo.com
}

Received October 19, 2014. Accepted October 22, 2014

\section{Abstract}

Background: Rapid modernization of the world requires more attention thereby aggravating eye strain in individuals, resulting into various types of headache disorders. Headache-related disorders are an important cause of disability worldwide, and ophthalmic causes for headache are well known.

Objectives: The aims of this study were: (i) to estimate the prevalence of headache disorders in patients attending the eye OPD; (ii) to evaluate the various causes of headache with special reference to ophthalmic conditions; and (iii) to study the correlation between location of headache and possible ocular causes.

Materials and Methods: A prospective study was carried out on 1520 patients from November 2006 to October 2009 at a tertiary eye care center. Detailed clinical history was taken with particular emphasis on onset, duration, location, intensity, character, diurnal variation, and exaggerating and relieving factors. Ocular examination included vision, slit-lamp examination, cycloplegic refraction, orthoptic evaluation, intraocular pressure measurement, and fundoscopy. Besides ocular examination, medical, ENT, dental, and neurological checkup along with investigations such as hemoglobin, blood sugar, X-ray of skull and paranasal sinuses, and CT scan of sinuses and brain were carried out whenever needed and treatment was advised accordingly. The data was entered on a Microsoft Excel spreadsheet and analyzed using SPSS software, version 14.0 (SPSS, Inc., Chicago, IL). $P$ value $<0.05$ was considered statistically significant.

Results: Our study included 1520 subjects complaining of headache. Maximum patients (47\%) were in the age group of 16-30 years with female preponderance (56\%). Ocular headache was found in $36 \%$ followed by primary headache $(27 \%)$, ENT problems $(17 \%)$, medical causes $(12 \%)$, and miscellaneous causes $(3 \%)$. Out of ocular causes of headache, refractive error $(65 \%)$ was the most common cause followed by abnormalities of anterior part of eye $(21 \%)$, muscles imbalance (18\%), and posterior segment disorders (5\%). Among various refractive errors, astigmatism was found in $41 \%$ cases, hypermetropia in $22 \%$, and myopia in $12 \%$ patients. In our study, $64 \%$ cases were relieved of headache

Conclusion: Headache is multifactorial in origin. Possibility of ocular causes should be kept in mind during management of headache. An ophthalmologist may play a vital role in establishing the correct diagnosis of headache.

KEY WORDS: Headache, squint, glaucoma, refractive errors, muscle imbalance, migraine

\section{Introduction}

Headache is an important cause of disability worldwide. ${ }^{[1]}$ It ought to be a huge public health issue, but receives little

\begin{tabular}{|l|l|}
\hline Website: htp://www.jmsph.com & Access this article online \\
\hline DOl: 10.5455/jimsph.2015.1910201454 & \\
\hline
\end{tabular}

priority in the queue for health-care resources. It mainly affects the productive years and carrier-making period of life and has a tremendous socioeconomic impact. Although it is a common complaint, it is often misdiagnosed and inadequately treated. Differential diagnosis of headache is probably one of the longest in all of the diseases. ${ }^{[2]}$ Headache may arise from conditions that range from benign to catastrophic. Rapid and accurate diagnosis is a crucial step for successful management of headache. The aims of this study were: (i) to estimate the prevalence of headache disorders in patients attending the eye OPD; (ii) to evaluate various causes of headache with special reference to ophthalmic condition; and (iii ) to study the correlation between location of headache and possible ocular causes. 


\section{Materials and Methods}

This prospective study carried out in the Department of Ophthalmology, SS Medical College and Gandhi Memorial Hospital, Rewa, Madhya Pradesh, India. It was conducted on 1520 patients complaining of headache during November 2006 and October 2009.

A detailed clinical history was taken with emphasis on onset, duration, location, intensity, character, diurnal variation, and exaggerating and relieving factors. Occupation of each patient was also recorded. Cases of manifest squint were excluded.

A comprehensive clinical examination including visual acuity of each eye for distance and near was conducted in all cases. Intraocular tension was taken with applanation tonometer and Humphrey visual field analysis were carried out to rule out any possibility of glaucoma.

All the patients were then subjected to thorough dark room investigations. Cover test (screen test) for distance and for near were conducted to rule out latent squint. Ocular movements were tested uniocularly and binocularly. Retinoscopic examination was carried out under appropriate cycloplegia. A postmydriatic test was done after 3 days if retinoscopy had been done under homatropine and after 2 weeks if it had been done under atropine. Orthoptic evaluation included measurement of the near point of convergence and power of accommodation. Maddox rod test was used for the measurement of heterophoria for distance and Maddox Wing test was used for near point of conversion. Near point of convergence and amplitude of accommodation were recorded by Royal Air Force ruler. Range of fusion and power of ductions were tested on the synoptophore in each patient. Examinations of the media and fundi were carried out under mydriasis. Patients whose diagnosis remained inconclusive on eye examination were referred to other departments such as medical, ENT, dental, neurology, or psychiatry, as required, and elicited by history and investigation. Besides these checkups investigations such as hemoglobin, blood sugar, skull X-ray and paranasal sinuses, and CT scan of sinuses and brain were carried out where needed and treatment was advised accordingly.

\section{Results}

The maximum incidence of headache $(46.84 \%)$ was found in the age group of 15-30 years, followed by in the age group of $31-45$ years $(29.07 \%)$ and in the age group $5-15$ years (16.44\%). The incidence was the lowest (i.e., $7.63 \%$ ) in the age group of more than 45 years [Table 1]. The incidence was higher in females $(56.44 \%)$ than males $(43.55 \%)$. Males and females ratio (in percent) in age group of 15-30, 30-45, and $>45$ years was 22:26, $12: 18$ and 3:5, respectively [Table 2]. Students were found to be most commonly affected (48\%) followed by housewives (25\%), clerks $(11.0 \%)$, businessman $(4 \%)$, technical personnel $(7 \%)$, and farmers and laborers $(4 \%)$
Table 1: Distribution of cases according to age of the patients

\begin{tabular}{lcc}
\hline Age (years) & No. of cases & Percentage \\
\hline $5-15$ & 250 & 16.44 \\
$16-30$ & 712 & 46.84 \\
$31-45$ & 442 & 29.07 \\
$>45$ & 116 & 7.63 \\
Total & 1520 & 100.0 \\
\hline
\end{tabular}

Table 2: Sex distribution in cases of headache

\begin{tabular}{lccccc}
\hline \multirow{2}{*}{$\begin{array}{l}\text { Age Group } \\
\text { (years) }\end{array}$} & \multicolumn{2}{c}{ Male } & & \multicolumn{2}{c}{ Female } \\
\cline { 2 - 3 } \cline { 5 - 6 } & $\begin{array}{l}\text { No. of } \\
\text { cases }\end{array}$ & Percentage & & $\begin{array}{l}\text { No. of } \\
\text { cases }\end{array}$ & Percentage \\
\hline $5-15$ & 116 & 7.63 & & 134 & 8.81 \\
$15-30$ & 228 & 21.57 & & 384 & 25.26 \\
$30-45$ & 176 & 11.57 & & 266 & 17.5 \\
$>45$ & 42 & 2.76 & & 47 & 4.86 \\
Total & 331 & 43.55 & & 858 & 56.44 \\
\hline
\end{tabular}

Table 3: Occupation of the patients having headache due to ocular causes $(n=546)$

\begin{tabular}{lcc}
\hline Occupation & No. of cases & Percentage \\
\hline Student & 262 & 47.98 \\
Housewife & 134 & 24.54 \\
Clerk & 30 & 10.98 \\
Businessman & 24 & 4.39 \\
Technical personnel & 38 & 6.95 \\
Laborer and farmer & 22 & 4.29 \\
Others & 3 & 1.09 \\
\hline
\end{tabular}

[Table 3]. The headache due to ophthalmic causes was found in $36 \%$ cases, followed by primary headache in $27 \%$, ENT problems in $17 \%$, medical causes in $12 \%$, and miscellaneous causes in $9 \%$ cases [Table 4]. Among ophthalmic causes, refractive error including presbyopia was seen in $65 \%$ cases, followed by anterior segment abnormalities in $21 \%$, muscles imbalance in $18 \%$, and diseases of posterior segment in $5 \%$ cases [Table 5]. Out of the $36 \%$ (546) cases with ocular abnormalities, $64.83 \%$ (354) had refractive errors. The most common refractive error was astigmatism, which observed in

Table 4: Etiological factors of headache

\begin{tabular}{lcc}
\hline Causes of headache & No. of cases & Percentage \\
\hline Primary headache & 404 & 26.57 \\
Ocular abnormalities & 546 & 35.92 \\
ENT & 252 & 16.57 \\
Medical & 188 & 12.36 \\
Miscellaneous & 130 & 8.55 \\
\hline
\end{tabular}


$42 \%$ cases followed anisometropia (25\%) and hypermetropia $(21.5 \%)$. The most common type of astigmatism was simple hypermetropic astigmatism (16\%), simple myopic astigmatism $(14.5 \%)$, compound myopic astigmatism $(6.5 \%)$, compound hypermetropic astigmatism (3\%) and mixed astigmatism (1\%) [Table 6].

Amount of astigmatism less than $1 \mathrm{D}$ was detected in $66 \%$ cases, whereas $23 \%$ cases had astigmatism between 1.5 and 2 D. Only $11 \%$ cases had astigmatism more than 2 D [Table 7]. Apart from astigmatism, other type of refractive errors comprised $51 \%$. Of these refractive errors $1 \mathrm{D}$ or less was seen in $62 \%$ cases. There were $26 \%$ cases having a refractive error between 1.25 and $2 \mathrm{D}$ and $12 \%$ were having a refractive error of more than $2 \mathrm{D}$. The incidence of hypermetropia was more in case with headache $(21.5 \%)$ [Table 8].

Headache is a symptom of anterior part of eye, glaucoma was found in $38 \%$ of the patients, followed by uveitis in $30 \%$,

Table 5: Various ocular causes of headache $(n=546)$

\begin{tabular}{lcc}
\hline Ocular causes & No. of cases & Percentage \\
\hline Refractive errors and presbyopia & 354 & 64.83 \\
Anterior segment abnormalities & 128 & 20.51 \\
Muscles imbalance & 44 & 17.94 \\
Diseases of posterior segment & 14 & 4.76 \\
Others & 6 & 2.19 \\
\hline
\end{tabular}

Table 6: Type of refractive errors in headache $(n=354)$

\begin{tabular}{lcc}
\hline Type of refractive error & No. of cases & Percentage \\
\hline Astigmatism & 150 & 42.37 \\
Simple hypermetropic astigmatism & 56 & 37.33 \\
Compound hypermetropic astigmatism & 14 & 9.33 \\
Simple myopic astigmatism & 50 & 33.33 \\
Compound myopic astigmatism & 22 & 14.66 \\
Mixed astigmatism & 8 & 5.33 \\
Hypermetropia & 76 & 21.46 \\
Presbyopia & 60 & 16.94 \\
Myopia & 44 & 12.42 \\
Mixed & 24 & 6.77 \\
\hline
\end{tabular}

Table 7: Amount of diaptoric power in various type of astigmatism in headache $(n=150)$

\begin{tabular}{|c|c|c|c|c|c|c|}
\hline \multirow[t]{2}{*}{$\begin{array}{l}\text { Type of } \\
\text { astigmatism (A) }\end{array}$} & \multicolumn{2}{|c|}{$\begin{array}{l}\text { Astigmatism } \\
\text { up to } 1 \mathrm{D}\end{array}$} & \multicolumn{2}{|c|}{$\begin{array}{c}\text { Astigmatism } \\
1.25-2 \mathrm{D}\end{array}$} & \multicolumn{2}{|c|}{$\begin{array}{c}\text { Astigmatism } \\
>2 \mathrm{D}\end{array}$} \\
\hline & $\begin{array}{l}\text { No. of } \\
\text { cases }\end{array}$ & $\%$ & $\begin{array}{l}\text { No. of } \\
\text { cases }\end{array}$ & $\%$ & $\begin{array}{l}\text { No. of } \\
\text { cases }\end{array}$ & $\%$ \\
\hline $\begin{array}{l}\text { Hypermetropic A } \\
\qquad(n=70)\end{array}$ & 44 & 29.33 & 20 & 13.33 & 6 & 4.00 \\
\hline Myopic A $(n=72)$ & 52 & 34.66 & 12 & 8.00 & 8 & 5.33 \\
\hline Mixed A $(n=8)$ & 4 & 2.66 & 2 & 1.33 & 2 & 1.33 \\
\hline Total 150 & 100 & 66.66 & 34 & 22.66 & 16 & 10.66 \\
\hline
\end{tabular}

corneal lesion in $23.43 \%$, and herpes zoster ophthalmicus in $9 \%$ of cases with headache [Table 9]. On orthoptic examination, $27 \%$ patients had exophoria for near convergence, $50 \%$ had convergence insufficiency or decreased convergence amplitude, and $23 \%$ had esophoria [Table 10]. Headache was aggravating more during near work in these subjects. Anterior headache was found in $68 \%$ cases, followed by posterior headache in $4 \%$ and combined headache in $12 \%$ of cases [Table 11]. The majority $(64 \%)$ of the headache patients were relieved of the symptoms [Table 12].

Table 8: Amount of diaptoric power in various type refractive error in headache $(n=180)$

\begin{tabular}{|c|c|c|c|c|c|c|}
\hline \multicolumn{7}{|c|}{ Amount of refractive error } \\
\hline \multirow{2}{*}{$\begin{array}{l}\text { Type of } \\
\text { refractive } \\
\text { error }\end{array}$} & \multicolumn{2}{|c|}{ Up to $1 \mathrm{D}$} & \multicolumn{2}{|c|}{$1.25-2 \mathrm{D}$} & \multicolumn{2}{|c|}{$2.25-5 \mathrm{D}$} \\
\hline & $\begin{array}{l}\text { No. of } \\
\text { cases }\end{array}$ & $\%$ & $\begin{array}{l}\text { No. of } \\
\text { cases }\end{array}$ & $\%$ & $\begin{array}{l}\text { No. of } \\
\text { cases }\end{array}$ & $\%$ \\
\hline $\begin{array}{l}\text { Hypermetropia } \\
\qquad(n=76)\end{array}$ & 52 & 28.88 & 16 & 8.88 & 8 & 4.44 \\
\hline $\begin{array}{l}\text { Presbyopia } \\
\qquad(n=60)\end{array}$ & 36 & 20.00 & 18 & 10.00 & 6 & 3.33 \\
\hline Myopia $(n=44)$ & 24 & 13.33 & 12 & 6.66 & 8 & 4.44 \\
\hline Total 180 & 112 & 62.22 & 46 & 25.55 & 22 & 12.21 \\
\hline
\end{tabular}

Table 9: Distribution of various types of anterior segment/adenaxal abnormalities $(n=128)$ that were found in causing headache

\begin{tabular}{lcc}
$\begin{array}{l}\text { Abnormalities of anterior } \\
\text { segment }\end{array}$ & No. of cases & Percentage \\
\hline Herpes zoster ophthalmicus & 12 & 9.37 \\
Glaucoma & 48 & 37.5 \\
Corneal ulcer/keratitis & 30 & 23.43 \\
Uveitis & 38 & 29.68 \\
\hline
\end{tabular}

Table 10: Incidence of muscles imbalance $(n=44)$ on cover test in patients with headache

\begin{tabular}{lcc}
\hline Muscles imbalance etiology & No. of cases & Percentage \\
\hline Exophoria & 12 & 27.2 \\
Esophoria & 10 & 22.72 \\
Defective convergence & 22 & 50.0 \\
\hline
\end{tabular}

Table 11: Location of headache in various ocular abnormalities $(n=546)$

\begin{tabular}{lcc}
\hline Location of headache & No. of cases & Percentage \\
\hline Anterior headache & 370 & 67.76 \\
Posterior headache & 110 & 20.14 \\
Combined headache & 66 & 12.08 \\
\hline
\end{tabular}


Table 12: Results obtained after treatment and on follow-up of cases of headache

\begin{tabular}{lcc}
\hline Treatment outcome & $\begin{array}{c}\text { No. of } \\
\text { patients }\end{array}$ & Percentage \\
\hline Cases completely relieved of headache & 972 & 63.94 \\
Cases partially relieved of headache & 334 & 21.97 \\
Cases did not turn up for subsequent & 214 & 14.07 \\
$\quad$ checkup & & \\
\hline
\end{tabular}

\section{Discussion}

Although headache is a common complaint, it has significant impact on public health as well as personal health. Though headache management is not always easy but it is often rewarding. The contribution of ophthalmologist in the diagnostic evaluation of a patient with headache is outlined. When asthenopia or an organic eye disease is the cause of the headache, the ophthalmologist can not only diagnose the etiology but also cure the patient by adequate therapy. When the headache is a sign of a central nervous system disease, the ophthalmologist can provide valuable information regarding nature and localization of the process to the neurologist. ${ }^{[3]}$

This study was carried out on 1520 patients experiencing headache and attending the Department of Ophthalmology, Gandhi Memorial Hospital, Rewa, between November 2006 and October 2009.

\section{Age Incidence}

In our study population, the maximum incidence of headache (i.e., $46.84 \%$ ) was found in the age group of 1530 years. In the age group of 30-45 years, the incidence was found to be $29.07 \%$. The incidence was the lowest (i.e., $7.63 \%$ ) in the age group of $>45$ years. Similar findings were reported by Dhir ${ }^{[4]}$ and Ahmed and Zuberi ${ }^{[5]}$ who found the maximum incidence of headache in the age group of 20-30 and $15-20$ years, respectively. Marasini et al. ${ }^{[6]}$ also observed in their study that every six patients out of ten have headache in the non-presbyopic adult group. Headache prevalence in this particular age group might be because of the psychological stress caused by educational pressures for career development, emotional factors, and family conflicts.

\section{Sex Incidence}

In our study, the incidence of headache was found to be higher in females $(56.5 \%)$ than in males $(43.55 \%)$ in all age groups. Our findings are consistent with findings of Lanchner, ${ }^{[7]}$ Donahue, ${ }^{[8]}$ and $\mathrm{Dhir}^{[4]}$ who reported incidence of headache in females to be $58.3 \%, 56 \%$, and $57 \%$ in their respective studies. Marasini et al. ${ }^{[6]}$ also reported females outnumbering males in their study. The higher incidence of headache in females may be due to their higher emotional instability and psychological stress in male-dominated society.
Occupation in Headache Cases Regarding Ocular Cause

In our study headache due to ocular causes was mostly seen in students (52\%). Brown and Kronfeld ${ }^{[9]}$ also reported $60 \%$ of student group having headache in their study.

\section{Various Causes of Headache}

In our study, the headache due to ophthalmic causes was found in $36 \%$ cases, followed by primary headache in $27 \%$, ENT in $17 \%$, medical causes in $12 \%$, and miscellaneous in $9 \%$ cases. Queiroz et al. ${ }^{[10]}$ found the prevalence of primary headache in general population as $37.2 \%$ and rest were having secondary causes. Our findings are discordant with their study because their study was population based whereas in our study, the cases were recruited from ophthalmic OPD.

\section{Ocular Causes of Headache}

In our study, the incidence of headache was a slightly higher in refractive errors including presbyopia in $65 \%$ cases, followed by muscles imbalance $18 \%$ and anterior segment abnormalities $21 \%$ cases. Similar findings were also observed by Cogan ${ }^{[11]}$ and Foster. ${ }^{[12]}$

\section{Types of Refractive Errors in Headache}

In our study the most common refractive error was astigmatism, which occurred in $42.37 \%$ cases followed by hypermetropia $(21.46 \%)$ and myopia $(12.42 \%)$. There was also a higher incidence of anisometropia (25\%). Ahmed and Zuberi $^{[5]}$ also found astigmatism in $59 \%$ and hypermetropia in $11 \%$ patients with headache. Marasini et al. ${ }^{[6]}$ found highest incidence of headache associated with refractive errors in $44 \%$ cases, among these astigmatism was observed in $63.63 \%$ subjects, hypermetropia in $27.27 \%$, and myopia in $9.09 \%$ cases. Mechanism of headache from ciliary muscles contraction in hypermetropia of equal or different degrees where patients accommodate to see clearly and in astigmatism, especially of low degree or moderate degree, where muscles contract irregularly may cause more severe headache.

\section{Amount of Refractive Errors in Headache}

In our study, 150 cases of headache had astigmatism in which 114 cases had astigmatism less than $1 D$ and 16 cases had astigmatism between $1.5 \mathrm{D}$ and $2 \mathrm{D}$.Only six cases had astigmatism more than $2 \mathrm{D}$. Similar observations were reported by Griffith ${ }^{[13]}$, who stressed that small astigmatism errors were responsible for more severe ocular asthenopia. Cogan $^{[11]}$ also stated that small refractive errors, especially hypermetropia and astigmatism, may cause headache. Akinci et al. ${ }^{[14]}$ also reported higher prevalence of headache in compound and mixed astigmatism. The reason for the higher incidence of headache in hypermetropic astigmatism and mixed astigmatism may be that involuntary, sustained excessive accommodative efforts put the eyes under strain. 
Anterior Segment/Adenaxal Abnormalities in Headache

We observed incidence of headache among the diseases of anterior part of eyes. Glaucoma was found in 38\% patients, followed by uveitis in $30 \%$, corneal ulcer/keratitis in $23 \%$, and herpes zoster ophthalmicus in $9 \%$ cases. Usui et al. ${ }^{[15]}$ also found $51 \%$ cases of glaucoma having migrainous headache.

\section{Muscular Imbalance in Headache Cases}

In our study, we found 44 cases of muscle imbalance with normal vision, of these $27 \%$ cases were exophorics and $23 \%$ were esophorics, and $50 \%$ cases were having defective convergence. These findings are in accordance with those reported in the study conducted by Dragomir et al. ${ }^{[16]}$ and Gupta et al. ${ }^{[17]}$ The authors reported that roughly $(60.4 \%)$ of young adult patients complaining of blurring of vision at near work and headache had convergence insufficiency. Dhir ${ }^{[3]}$ also noticed muscle imbalance for near (mainly exophoria) to be more important in causing headache. Possible explanation is that binocularity and parallelism are maintained by the extraocular muscles under the controlling influence of fusion. In muscle imbalance, this might put a strain on the extraocular musculature that is richly supplied with pain-sensitive nerve endings and lead to ocular asthenopia and headache.

\section{Location of Headache Regarding Ophthalmic Cause}

In our study, the anterior headache was found in $67 \%$ cases, followed by posterior headache in $20 \%$ of cases and combined headache in $12 \%$ of cases. Our findings are in accordance with those of Lanchner ${ }^{[7]}$ who found $56 \%$ of cases to have anterior headache and $14 \%$ to have posterior headache. Foster ${ }^{[12]}$ found cases of posterior headache in $12 \%$ of cases. Posterior headache was most common in cases of presbyopia, myopia, and convergence insufficiency. The occurrence of posterior headache in presbyopia may be because of abnormal posture (like titling back of the head) stimulating the pain-sensitive endings in the neck and back of the head. Griffith ${ }^{[13]}$ also explained occipital pain on account of eye strain, which may lead to screwing of the eyes and contraction of the orbicularis and frontalis which in turn pulls on epicranial fascia and occipital muscles leading to contraction of these. Mechanism of anterior headache from contraction of ciliary muscles in hypermetropia of equal or different degrees where patients accommodate to see clearly, screwing of lids in myopia, and also iris muscle contraction and dilatation in flicker light, may cause more severe headache.

\section{Relief of Headache in Study Group}

We found that $64 \%$ cases were completely relieved of the symptoms. Approximately $14 \%$ cases did not turn up. Although there is no consensus about the headache management, but on conducting a statistical study of probable causes of ocular headache it was found that occurrences of anterior headaches were more common.

\section{Conclusion}

Headache, which is one of the most common symptom, may occur due to innumerable causes and sometime it is difficult to establish its mechanism in many cases. Proper headache management needs complete understanding of all agonies of patients. Sufficient time committed to a systematic headache history is the key to effective diagnosis and successful management. Ophthalmic disorders responsible of headache are many. An ophthalmologist has a vital role in the management of headache. A detailed clinical history and a multidisciplinary approach in a stepwise manner will greatly help in exploration of the cause of headache. It also provides an opportunity to establish a good doctor-patient rapport and decreases the burden of disorder rather than shunting patient from doctor to doctor.

\section{References}

1. Vos T, Flaxman AD, Naghavi M, Lozano R, Michaud C, Ezzati M, et al. Years lived with disability (YLD) for 1160 sequelae of 289 diseases and injuries 1990-2010: a systematic analysis for the Global Burden of Disease Study 2010. Lancet 2012; 380:2163-96.

2. Martin TJ, Soyka D. Ocular causes of headache. In: The Headaches, Olesen J, Tfelt-Hansen P, Welch KMA (Eds). New York: Raven Press, 1993. p. 748.

3. Neuhann T. [Headache and the eye]. Fortschr Med 1982; 100:1333-7.

4. Dhir BK. Convergence insufficiency. Indian J Ophthalmol 1961; 9:33-5.

5. Ahmed SH, Zuberi H. Depression anxiety and headache. J Pak Med Assoc 1981;31:276-9.

6. Marasini S, Khadka J, Sthapit PRK, Sharma R, Prasad B. Ocular morbidity on headache ruled out of systemic causes-a prevalence study carried out at a community based hospital in Nepal. Nepal J Optom 2012;5:68-74.

7. Lanchner AJ. Headache in ophthalmic practice. Neurology 1952;2:471-6.

8. Donahue HC. Some current concepts of headache, especially ocular. AMA Arch Ophthalmol 1958;59:489-94.

9. Brown EVL, Kronfeld PC. The acuity of binocular depth perception in hemianopsia.Trans Am Ophthalmol Soc 1930; 28:231-49.

10. Queiroz LP, Barea LM, Blank N. An epidemiological study of headache in Florianopolis, Brazil. Cephalalgia 2006;26:122-7.

11. Cogan DG. Popular misconceptions pertaining to ophthalmology. New Engl J Med 1941;224:462-6.

12. Foster CB. Headache as a symptom of visual disability. Am J Ophthalmol 1950;33:773-6.

13. Griffith $\mathrm{A}$. The eyes as a cause of headache. $\mathrm{Br}$ Med $\mathrm{J}$ 1934;2:296-7.

14. Akinci A, Güven A, Degerliyurt A, Kibar E, Mutlu M, Citirik M. The correlation between headache and refractive errors. J AAPOS 2008;12:290-3.

15. Usui T, Iwata $\mathrm{K}$, Shirakashi M, Abe $\mathrm{H}$. Prevalence of migraine in low-tension glaucoma and primary open-angle glaucoma in Japanese. Br J Ophthalmol 1991;75:224-6. 
16. Dragomir M, Trus L, Chirila D, Stinger C. Orthoptic treatment efficiency in convergence insufficiency treatment. Oftalmologia 2001;53:66-9.

17. Gupta A, Kailwoo SK, Vijayawali. Convergence insufficiency in patients visiting eye OPD with headache. JK Science 2008; 10:135-6.
How to cite this article: Jain S, Chandravanshi SL, Dukariya L, Tirkey ER, Jain SC. Clinical study of headache with special reference to ophthalmic cause. Int J Med Sci Public Health 2015;4: 292-297

Source of Support: Nil, Conflict of Interest: None declared. 